\title{
In situ X-Ray diffraction study of hydrogen sorption in V-rich Ti-V-Cr bcc solid
} solutions

\author{
Damien PLANTE $^{\mathrm{a}, \mathrm{b}}$, Jérôme ANDRIEUX ${ }^{\mathrm{c}, \mathrm{d}}$, Laetitia LAVERSENNE $^{\mathrm{a}, \mathrm{b}}$, \\ Salvatore MIRAGLIA ${ }^{\mathrm{a}, \mathrm{b}}$
}

${ }^{a}$ CNRS, Inst. NEEL, F-38042 Grenoble, France

${ }^{b}$ Univ. Grenoble Alpes, Inst. NEEL, F-38042 Grenoble, France

${ }^{c}$ ID15, ESRF, 6 rue Jules Horowitz, 38043 Grenoble, France

${ }^{d}$ Université Claude Bernard Lyon 1, LMI-UMR CNRS N ${ }^{\circ}$ 5615, 43 Bd du 11 novembre 1918, 69622 Villeurbanne Cedex, France

\begin{abstract}
Alloying of vanadium with a combination of titanium and chromium has been investigated in this study. Hydrogenation/desorption of several alloys under similar experimental conditions has been performed and sequentially followed by means of in situ X-Ray powder diffraction. This latter technique has been used as a probe of formation or decomposition of hydrides. Geometrical effects are discussed and accounted for the observed similarities of the sorption properties.
\end{abstract}




\section{Introduction}

Ti-based bcc solid solutions have been intensively investigated over the last decade since they were reported by Akiba and co-workers [1-4]. Their interstitial hydrides are promising candidates for reversible hydrogen storage. Their high volumetric hydrogen storage density makes them suitable for onboard applications. Portable or standalone applications have to meet more or less the same requirement that is a compact, light, safe and affordable containment. For this purpose, the Ti-V-Cr class of materials in the bcc solid solution range has been proposed in the framework of the French national project HY-CAN aimed at developing an integrated portable system made of a hydrogen storage unit coupled with a fuel cell. Alloying of vanadium with a combination of titanium and chromium has been investigated in this study since the required operating pressure and temperature range for portable devices point to the vanadiumrich side of the Ti-V-Cr system and the corresponding hydrides.

Early studies [5] teach us that at the V-rich side, alloys with $\mathrm{Ti} / \mathrm{Cr}=0.84$ [6] and 0.66 show effective capacities above $2 \mathrm{wt} \%[6,7]$. We therefore selected different $\mathrm{V}_{\mathrm{x}}\left(\mathrm{Ti}_{0.8} \mathrm{Cr}\right)_{1-\mathrm{x}}$ compositions for which, according to literature, no C14 type Laves phase would develop in the as-cast state at such stoichiometries. Hydrogenation and desorption of several alloys/hydrides under the same experimental conditions has been performed and sequentially followed by means of in situ X-Ray powder diffraction. This latter technique has been used as a probe of formation or decomposition of the hydrides.

\section{Experimental method and details}




\section{Materials synthesis}

The samples were induction-melted in a HF furnace from ingots of $\mathrm{Ti}(\mathrm{Neyco}, 3 \mathrm{~N}), \mathrm{V}(\mathrm{Neyco}$, $3 \mathrm{~N})$ and $\mathrm{Cr}(\mathrm{Neyco}, 3 \mathrm{~N})$. Then a secondary minor phase $\left(\mathrm{Zr}_{7} \mathrm{Ni}_{10} 4 \mathrm{wt} \%\right)$ was incorporated according to a procedure described elsewhere [8]. The addition of this latter activating phase results in a reduction of the incubation time and facilitates the initial activation of the bcc samples. The resulting alloys were ball milled for 6 x $5 \mathrm{mn}$ in a Fritsch planetary miller operated at $160 \mathrm{rpm}$ with a powder to ball weight ratio equal to 20 . The handling of all the powders was done in a glove box containing argon with $\mathrm{O}_{2}$ and $\mathrm{H}_{2} \mathrm{O}$ contents $<1 \mathrm{ppm}$. The agreement between the target composition and the resulting sample was checked by means of EDX analysis available in the course of SEM characterization (not shown in this paper). For the purpose of the study, four different compositions were selected changing the $\mathrm{V} /\left(\mathrm{Ti} i_{0.8} \mathrm{Cr}\right)$ ratio. The compositions that have been investigated are $\left.\mathrm{V}_{\mathrm{x}}\left(\mathrm{Ti}_{0.8} \mathrm{Cr}\right)_{1-\mathrm{x}}\right)$ with $1-\mathrm{x}=0.1(\mathrm{BBC} 1), 0.2$ (BCC2), 0.3 (BCC3) and 0.4 (BCC4).

\section{In situ synchrotron X-ray diffraction}

In order to perform real-time studies of solid-gas reactions involving hydrogen, a dedicated cell was developed for in situ X-ray powder diffraction at high energy ( $90 \mathrm{keV})$ on the ID15 beamline at ESRF [9]. The sample was introduced into a $3 \mathrm{~mm}$ internal diameter sapphire capillary under inert atmosphere (glove box). The capillary was connected to a dedicated HighPressure High-Temperature gas loading system fitted to an X-ray transparent furnace. The latter enables accurate sample temperature control during the diffraction experiment. The fast detector Pixium 4700 was used with an acquisition time of $1.6 \mathrm{sec}$ at a frequency of $5 \mathrm{sec}$. A lead mask was specially designed and applied on the detector surface to shield the diffraction signal of the single-crystal sapphire capillary. The beam size illuminating the sample was $0.3 \mathrm{x}$

$0.3 \mathrm{~mm}^{2}$. The exact wavelength, $\lambda=0.1423(31) \AA$, was determined by using $\mathrm{CeO}_{2}$ as a reference 
sample. Finally, the diffraction pattern was obtained by radial integration of the raw image corrected from polarization, geometrical artefacts and detector efficiency.

\section{Description of the hydrogenation procedure and operando structural refinement details}

Prior to the in situ diffraction experiment the samples were subjected to 5 absorption/desorption cycles (room temperature, $\mathrm{P}_{\mathrm{H} 2}=3 \mathrm{MPa}$ ) in order to ensure a good reactivity. Hydrogenated samples were then introduced in the sapphire capillary. The operando diffraction experiment was composed of the following sequences: (1) dehydrogenation: the sample was heated up to $550^{\circ} \mathrm{C}$ at $10^{\circ} \mathrm{C} / \mathrm{min}$ under an argon flow of $0.5 \mathrm{Nl} / \mathrm{min}$. (2) plateau: the temperature was then held at $550^{\circ} \mathrm{C}$ for 10 min under primary vacuum (1 Pa) (3) rehydrogenation under a constant $\mathrm{H}_{2}$ pressure of $4 \mathrm{MPa}$ and decreasing temperature at a rate of $10^{\circ} \mathrm{C} / \mathrm{min}$. The structural study was performed using the Rietveld refinement method and the FullProf suite software that allows sequential refinements of the diffraction patterns to be performed [10]. Refined parameters for the sequential analysis include the lattice parameters and intensity scale factor. The atomic positions were kept fixed (see comments in the next section) as well as the isotropic thermal factor and peak shape profile parameters. The background points were selected for each pattern. The pseudo-Voigt function with axial divergence correction was used for an analytical description of the peak shape. The instrument resolution function was defined using $\mathrm{LaB}_{6}$ as a standard.

\section{PC isotherms measurements}

PCI (Pressure Composition Isotherms) measurements as well as sorption analyses (Sievert method) were done on a HIDEN Isochema HTPS apparatus. Prior to measurements, the samples were activated at room temperature $\left(20^{\circ} \mathrm{C}\right)$, under a $\mathrm{H}_{2}$ pressure of $3 \mathrm{MPa}$ and subjected to 
several absorption/desorption cycles. This activation procedure was followed by a complete desorption at $400^{\circ} \mathrm{C}$ under vacuum. The PC isotherms were then recorded at $20^{\circ} \mathrm{C}$.

\section{Results and discussion}

In situ diffraction study and structural information obtained from sequential single pattern analysis

Figure 1 displays a typical in situ data set that shows the evolution of the diffraction lines and the associated time/temperature scale in the course of which hydrogenation has taken place. A gray-scale contour plot represents the scattering intensity: the brighter peak, the higher intensity. The different peaks corresponding to the start and end crystal phases are rather easily identified and show the unambiguous formation of the fcc dihydride for each composition. Regarding the sequential refinement of the diffraction patterns, the conventional Bragg factors $\left(\mathrm{R}, \mathrm{R}_{\mathrm{f}}\right.$ ) lied in the range 3-9 demonstrating the quality of the refinements. Note that these factors went up to 14 for some patterns lying in the boundary phase region. The low scattering power of hydrogen when using X-rays combined to the resolution of the ID15 beamline does not allow to accurately locate hydrogen within the metal framework. Therefore using trial and error refinements, the following structural descriptions were used for the hydrides. Hydrogen was located in the regular tetrahedral sites of the interstitial V-H solid solution ( $\alpha$ phase), the same was done for the di-hydride ( $\gamma$ phase) where hydrogen was accommodated in the regular tetrahedral sites of the $\mathrm{CaF}_{2}$ type structure. Regarding the mono-hydride ( $\beta$ phase), it is known that published V-H phase diagrams [11] indicate other phases ( $\beta_{1}$ and $\beta_{2}$ phases) that are simple variants of the body-centered tetragonal (bct) $\beta-\mathrm{V}_{2} \mathrm{H}$ monohydride structure arising from either ordering or disordering of additional hydrogen on the octahedral interstitial sites $[12,13]$. Powder XRD cannot easily distinguish between these phases; hence, the regular description of 
the bct phase was used for the refinements. Accommodation of hydrogen in further octahedral sites did not result in significant improvements of the refinement quality. For each sample in the course of the desorption and absorption processes, the sequential refinements allowed to keep track of the structural parameters and of the weight fraction of each phase. The boundary phase limits (ie time/temperature of the formation or decomposition of the hydrides) could also be determined.

\section{Desorption}

At the end of the activation process described in the experimental section, the samples were in the monohydride state. Figures $2 \mathrm{a} \& 2 \mathrm{~b}$ show the evolution of the $\beta$-phase fraction in the course of the dehydrogenation process. In figure $2 \mathrm{a}$ the inflexion points are associated to structural variations that might reflect the cell transformations associated to the formation of $\beta_{1}$ and $\beta_{2}$ phases. Figure 2a shows that under such experimental conditions a complete desorption of the monohydride is achieved for samples $\mathrm{BCC} 1$ and $\mathrm{BCC} 2$, whereas samples $\mathrm{BCC} 3$ and $\mathrm{BCC} 4$ contain a remaining beta phase fraction of $53 \%$ and $38 \%$ respectively at $500^{\circ} \mathrm{C}$. This qualitative behavior allows to distinguish the weak-alloyed vanadium samples (BBC1 \& BCC2 with alloying ratios $<20$ at\%) from the high-alloyed ones (BCC3 \& BCC4). The same kind of plot as a function of elapsed time (figure $2 \mathrm{~b}$ ) gives an indication of the desorption kinetics (slope of the curves fits); it is seen that the high-alloyed samples have lower desorption kinetics.

By using the Williamson-Hall (WH) method [14], peak profile analysis yields information on grain size and crystallite strain. This method relies on the principle that the approximate formulae for size broadening, $\beta_{\mathrm{L}}$, and strain broadening, $\beta_{\mathrm{e}}$, vary quite differently with respect to Bragg angle. When both contributions are present then their combined effect are determined by convolution. WH method assumes that the convolution is either a simple sum or sum of 
squares. Then, comparing the WH plots to the standard equation for a straight line and by plotting $\beta_{\text {tot }} \cos \theta$ versus $\sin \theta$ ( $\beta_{\text {tot }}$ is the total peak width) we obtain the strain component from the slope and the size component from the intercept.

WH- type plots have been drawn at various temperatures and an example is given on figure 3a at $400^{\circ} \mathrm{C}$. On such plots we can see a clear distinction between weak-alloyed samples (BCC1, BBC2) and high-alloyed samples (BCC3, BCC4) with different slope factors meaning different strain contributions to the peak broadening. These experimental observations indicate that alloying of vanadium induces structural strain that accordingly increases with the alloying rate. An inspection of the slopes values at selected temperatures (see figure $3 \mathrm{~b}$ ) in the vicinity of the phase boundary regions does not show significant variations of the slope factor. This means that structural strain is not relieved upon structural transformation.

\section{Absorption}

In spite of the lower desorption kinetics observed for samples BCC3 \& BCC4, the 10 min plateau sequence at $550^{\circ} \mathrm{C}$ is sufficient to completely remove hydrogen from sample BCC4. Therefore, the starting configuration prior to hydrogenation $\left(3^{\text {rd }}\right.$ sequence) is the same for all samples (hydrogen free) except for BCC3 for which the starting configuration is a mixed state $(\alpha$ phase $(47 \%)+\beta$ phase $(53 \%))$. The evolution of the weight fraction for each sample as a function of temperature is reported in Figure 4. Figure 4a shows that the monohydride forms at the same temperature for every (non hydrogenated) sample, figure $4 \mathrm{~b}$ shows that the formation temperature of the di-hydride phase is very close for every sample (around $60^{\circ} \mathrm{C}$ ).

\section{Hydrogenation properties from PCI measurements}


Figure 5 shows the $20^{\circ} \mathrm{C}$ PC isotherms of the four samples. The plateau width corresponds to the maximal reversible capacity of the $\gamma$ phase and is similar for every sample $(\sim 1.7 \mathrm{wt} \%)$. Because of the poor sensitivity of the PCI set up at low pressures, equilibrium isotherms below 0,01 MPa could not be recorded. For each sample, an almost equal and significant hydrogen uptake $(1.4 \mathrm{wt} \%)$ is measured and can be ascribed to the capacities of lower hydrides $(\beta 1, \beta 2)$ and the hydrogen solid solution $(\alpha)$ with higher stability. It is interesting to compare these measured values with those derived from X-ray diffraction. According to Fukai [15] the hydrogen-induced volume $\mathrm{v}_{\text {н }}$ for $\mathrm{d}$ band metals and tetrahedral sites occupancy is about $2.5 \AA^{3}$. In situ X-ray diffraction allows to directly measure the hydrogen-induced volume increase (normalized to one formula unit), then by using the value of $\mathrm{v}_{\mathrm{H}}$ the hydrogen uptake can be easily derived. Table 1 summarizes the useful structural data and the corresponding hydrogen uptake, a remarkably good consistency between the PCI and XRD-extracted values was found.

\begin{tabular}{|l|l|l|l|l|l|l|l|l|l|}
\hline sample & $\begin{array}{l}\text { Starting } \\
\text { volume } \\
\boldsymbol{\alpha} \text { phase }\end{array}$ & $\begin{array}{l}\text { End } \\
\text { volume } \\
\boldsymbol{\alpha} \text { phase }\end{array}$ & $\begin{array}{l}\text { Volume } \\
\text { expansion }\end{array}$ & $\begin{array}{l}\mathbf{H} \\
\text { uptake }\end{array}$ & $\begin{array}{l}\text { Starting } \\
\text { volume } \\
\beta \text { phase }\end{array}$ & $\begin{array}{l}\text { End } \\
\text { volume } \\
\beta \text { phase }\end{array}$ & $\begin{array}{l}\text { Volume } \\
\text { expansion }\end{array}$ & $\begin{array}{l}\mathbf{H} \\
\text { uptake }\end{array}$ & $\begin{array}{l}\text { Total } \\
\text { uptake }\end{array}$ \\
\hline BCC 1 & $28.58(2)$ & $31.74(2)$ & $3.16(2)$ & 0.70 & $28.6(1)$ & $31.8(1)$ & $3.2(1)$ & 0.7 & 1.4 \\
\hline BCC2 & $28.63(4)$ & $31.64(4)$ & $3.01(4)$ & 0.67 & $28.6(1)$ & $31.7(1)$ & $3.1(1)$ & 0.7 & 1.4 \\
\hline BCC3 & $28.3(1)$ & $30.7(1)$ & $2.3(1)$ & 0.5 & $28.3(1)$ & $31.6(1)$ & $3.3(1)$ & 0.7 & 1.2 \\
\hline BCC4 & $28.72(3)$ & $31.31(4)$ & $2.59(3)$ & 0.57 & $28.7(1)$ & $31.4(1)$ & $2.7(1)$ & 0.5 & 1.1 \\
\hline
\end{tabular}

Table 1: Hydrogen-induced volume expansion of $\left(\mathrm{Ti} i_{0.8} \mathrm{Cr}\right)_{1-x} V_{x}$ samples

Another interesting feature of figure 5 is the large plateau hysteresis, it increases with the alloying fraction. Using a mid-plateau pressure (because of slope effect) the calculated enthalpies vary from -37 to $-39 \mathrm{~kJ} / \mathrm{mol} \mathrm{H}_{2}$ - upon absorption and from -42 to $-45 \mathrm{~kJ} / \mathrm{mol} \mathrm{H}_{2}$ upon desorption. Here again the weak- alloyed vanadium samples (alloying ratio < 20 at\%) can be distinguished from the high-alloyed ones. This observation means that cycling is not effective to relieve the stress associated to alloying. 


\section{Summary and conclusion}

It is known that, because of the monohydride stability, only about a half of the amount of the hydrogen absorbed in vanadium or alloyed vanadium can be practically used for reversible applications. The issues for increasing the usable storage capacity are to reduce the solubility limit ( $\alpha$ phase) and decrease the stability of upper hydrides ( $\beta$ and $\gamma$ ). The early studies of Reilly et al [16] have shown that alloying with a single metallic element affords a method of varying the electronic, crystallographic and thermodynamic characteristics of the parent metal. Therefore, the relative stabilities of the hydrides may be modified by alloying. The effect of Ti alloying [17] as well as that of Cr alloying [16] have been investigated and it turns out that these two elements have an opposite effect upon the hydride phase stability [18]. The situation is more complex with (Ti-Cr) alloying.

Our study demonstrates that alloying of vanadium up to $40 \%$ with the particular ratio of $\mathrm{Ti} / \mathrm{Cr}$ $=0.8$ results in very minor changes of the hydrogenation properties. The in situ X-ray diffraction study has shown that the structural transformations associated to hydride formation take place at the same temperature. Moreover, mixed phase regions exist for every sample under our experimental conditions. PCI characterization shows very similar isotherms for every sample in terms of plateau widths and equilibrium pressures.

A careful literature survey reveals that our experimental observations corroborate and are consistent with some already observed features. In the early work of Akiba [5], it is noticed that the equilibrium pressure of the Ti-V-Cr-H system is very sensitive to changes of the lattice parameter which in turn is itself related to the Ti/Cr ratio; a similar conclusion was reached by Okada et al. [19] and more recently by Tsukahara [20]. In our study, the investigated samples have an equal Ti/Cr ratio, their lattice parameters at room temperature are listed in Table 2 and 
may be considered almost constant. It is then interesting to introduce the size of the interstitial hole available for hydrogen accommodation in bcc solid solutions.

\begin{tabular}{|l|l|l|l|l|}
\hline sample & BCC1 & BCC2 & BCC3 & BCC4 \\
\hline $\begin{array}{l}\text { Lattice parameter } \\
\AA\end{array}$ & $3.026(1)$ & $3.028(1)$ & $3.0307(6)$ & $3.032(1)$ \\
\hline
\end{tabular}

Table 2: Room temperature lattice parameters of $\left(\mathrm{Ti} i_{0.8} \mathrm{Cr}\right)_{1-x} \mathrm{~V}_{x}$ samples

Using geometrical considerations [21, 22], the radius of insertion of the interstitial hole can be calculated as $\frac{\sqrt{5}}{4} \boldsymbol{a}-\boldsymbol{r}_{\boldsymbol{M}}$. Using the following atomic radii for a conventional 8 -fold coordination: $r_{\mathrm{V}}=1.309 \AA, r_{\mathrm{Ti}}=1.314 \AA, r_{\mathrm{Cr}}=1.249 \AA ; r_{\mathrm{M}}$ is calculated as the compositional average of the atomic radii. The calculations show that the interstitial site radius is almost the same for every sample and ranges from $r_{\mathrm{H}}=0.386 \AA$ to $r_{\mathrm{H}}=0.397 \AA$. This may explain why the equilibrium pressure does not vary much in the investigated series of samples meaning that geometrical effects (size of the interstitial site) are more important than chemical effects (chemical nature of the coordinating species) and account for the observed similarities of the sorption properties.

\section{Acknowledgements}

The authors are grateful to the European Radiation Synchrotron Facility for the provision of beamtime. One author (DP) acknowledges funding from FUI HYCAN and the City of Grenoble. 


\section{References}

[1] J. Huot, E. Akiba, H. Iba, J. Alloys Compd. 228 (1995) 181-187.

[2] J. Huot, E. Akiba, Y. Ishido, J. Alloys Compd. 231 (1995) 85-89.

[3] H. Iba, E. Akiba, J. Alloys Compd. 231 (1995) 508-512.

[4] H. Iba, E. Akiba, J. Alloys Compd. 253-254 (1997) 21-24

[5] E. Akiba, H. Iba Intermetallics 6 (1998) 461-470

[6] H. Jeong, I. Kim, K. Y. Choo,, J. S. Sung,T. H. Kim in proceedings of the 17 th World Hydrogen Energy Conference, Brisbane, Australia 15 - 19 June 2008 ISBN 9781615674541

[7] M. Okada , T. Kuriiwa, T. Tamura, H. Takamura and A. Kamegawa Metals and Materials International, Vol. 7, No. 1 (2001) 67-72

[8] S. Miraglia, P. de Rango, S. Rivoirard, D. Fruchart, J. Charbonnier, N. Skryabina J. Alloys Compd. 536 (2012) 1-6

[9] J. Andrieux, C. Chabert, A. Mauro, H. Vitoux, B. Gorges, T. Buslaps and V. Honkimaki J. Appl. Cryst. (2014). 47, 245-255

[10] J. Rodriguez-Carvajal Physica B: Condensed Matter 192 (1993) 55-69

[11] J.F. Smith and D.T. Peterson, in Phase Diagrams of Binary Vanadium Alloys, edited by J. F. Smith (ASM International, Metals Park, OH, 1989) p. 106;

(b) T.Schober, Solid State Phenomena 49-50 (1996) 357.

[12] D.G. Westlake, MH Mueller, HW Knott J. Appl. Cryst.6 (1973) 206

[13] J. Wanagel, SL Sass, BW Batterman Phys. Stat. Sol. (a) 10 (1972) 49-57

[14] G.K.Williamson, W.H.Hall Acta Metall. 1, (1953) 22-31

[15] Y. Fukai The metal hydrogen system Springer Series on Materials Science vol 21(2001)

[16] J.F. Lynch, J.J. Reilly, F. Millot J. Phys. Chem Solids 39 (1978) 883-890.

[17] A. Kagawa, Reports of the Faculty of Engineering, Nagasaki University, Vol. 25, No. 45 (1995) p. 233

[18] H. Yukawa, M. Takagi, A. Teshima, M. Morinaga J. Alloys Compd 330-332 (2002) 105109

[19] M. Okada, T. Choub, A. Kamegawa, T. Tamura, H. Takamura, A. Matsukawa, S. Yamashita J. Alloys Compd 356-357 (2003) 480-485 
[20] M. Tsukahara, Materials Transactions, Vol. 52, No. 1 (2011) pp. 68 to 72

[21] K. Kubo, H. Itoh, T. Takahashi, T. Ebisawa, T. Kabutomori, Y. Nakamura, E. Akiba J. Alloys Compd 356-357 (2003) 452-455

[22] D.G. Westlake, J. Less-Common Met. 91 (1983) 275-292. 


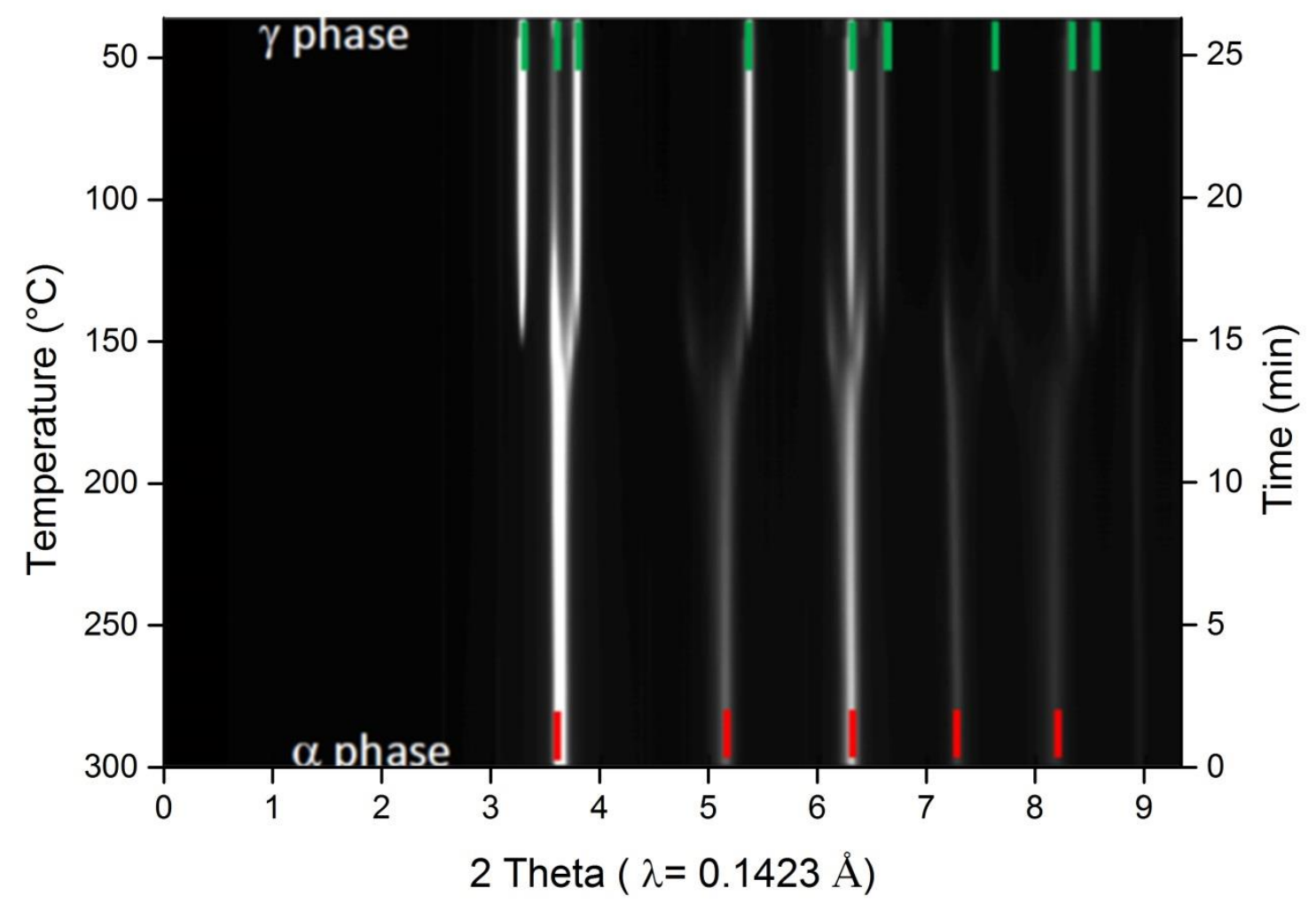

Figure 1: Time-resolved X-ray diffraction patterns of sample $\mathrm{BCC} 1$ during the absorption process. Lighter tones (bright white) indicate higher intensities. 


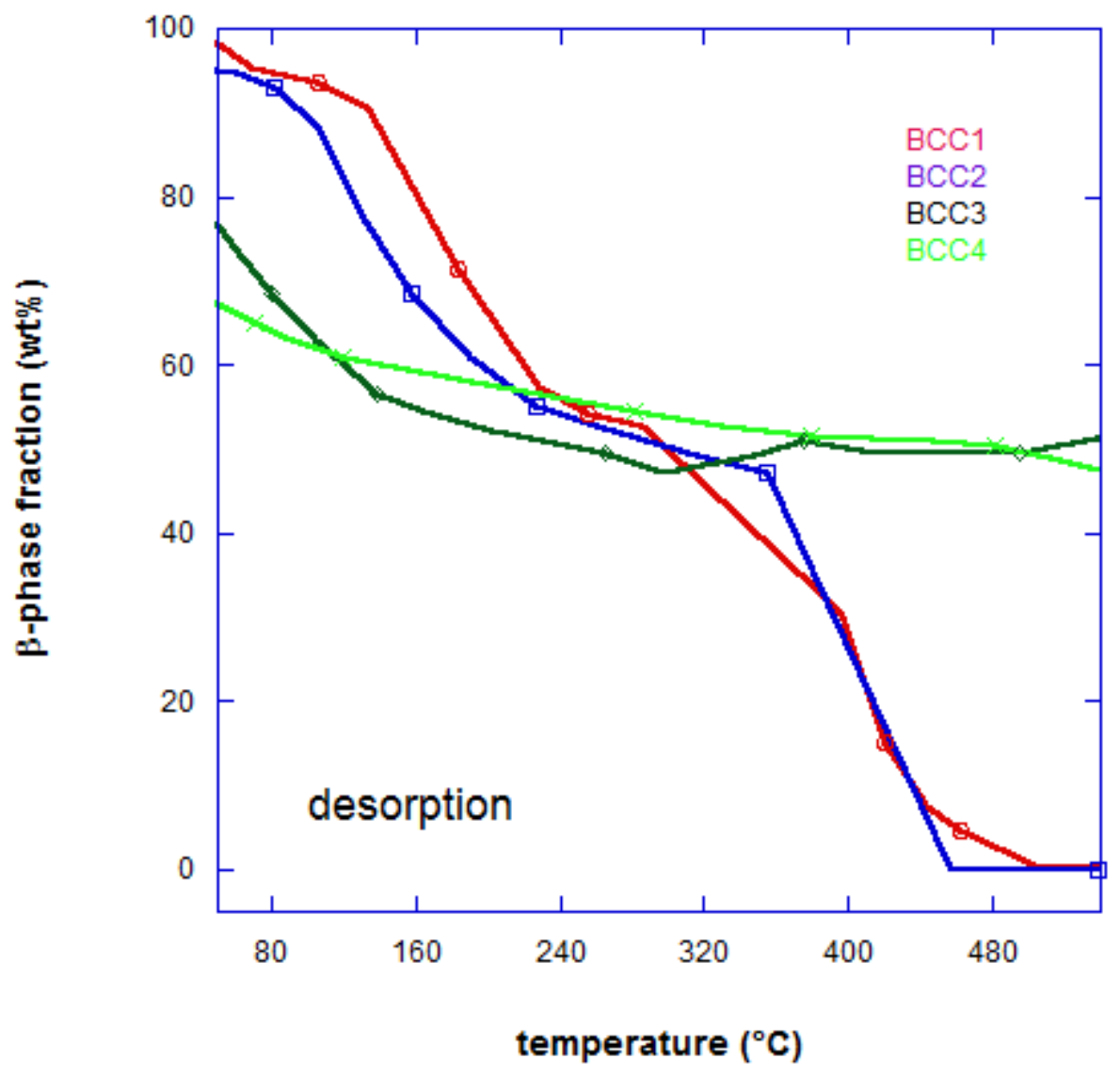

Figure 2a: Evolution of the $\beta$ phase weight fraction in the course of the dehydrogenation process (increasing temperature). 


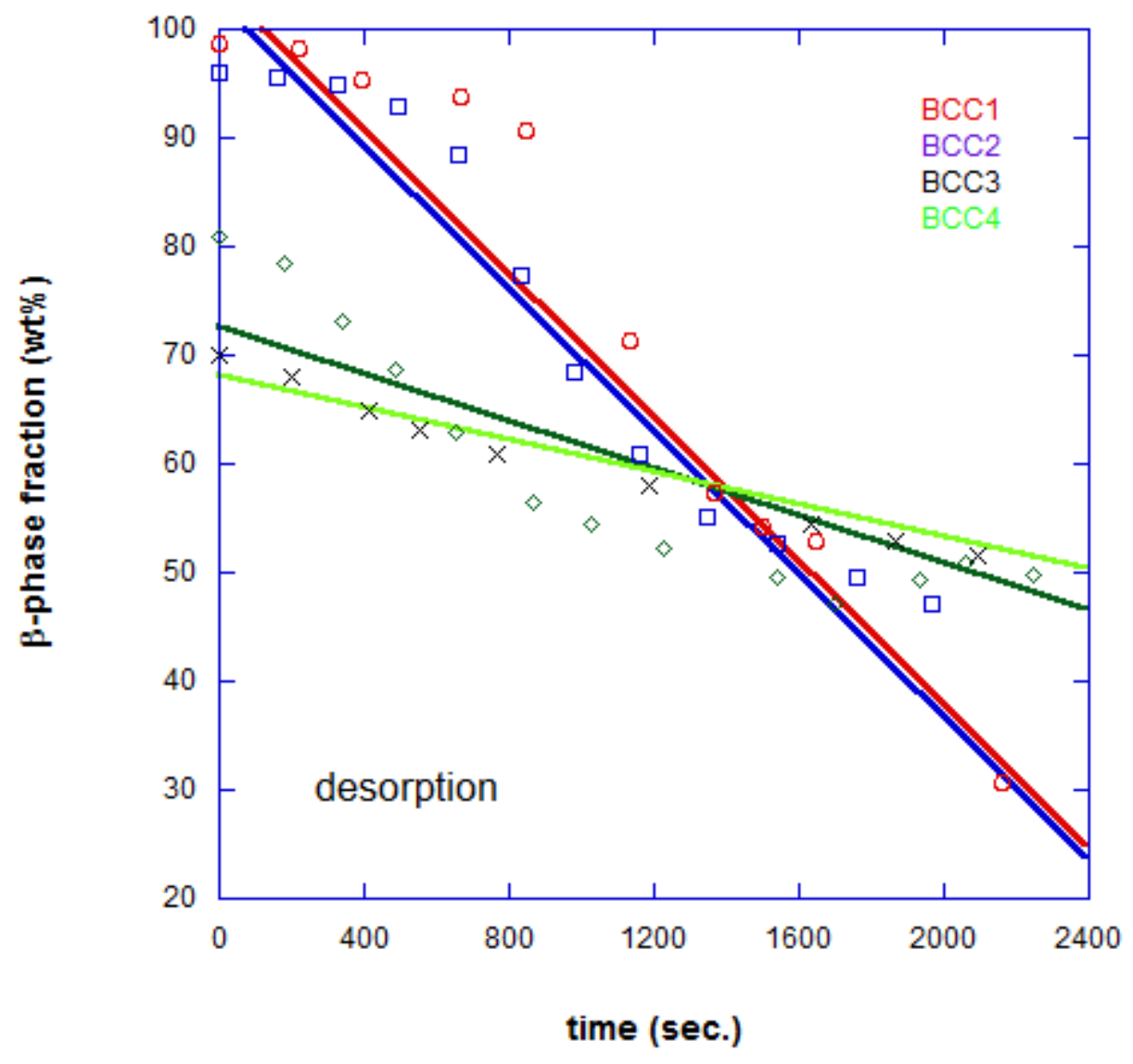

Figure $2 \mathrm{~b}$ : Evolution of the $\beta$ phase weight fraction in the course of the dehydrogenation process as a function of the elapsed time. 


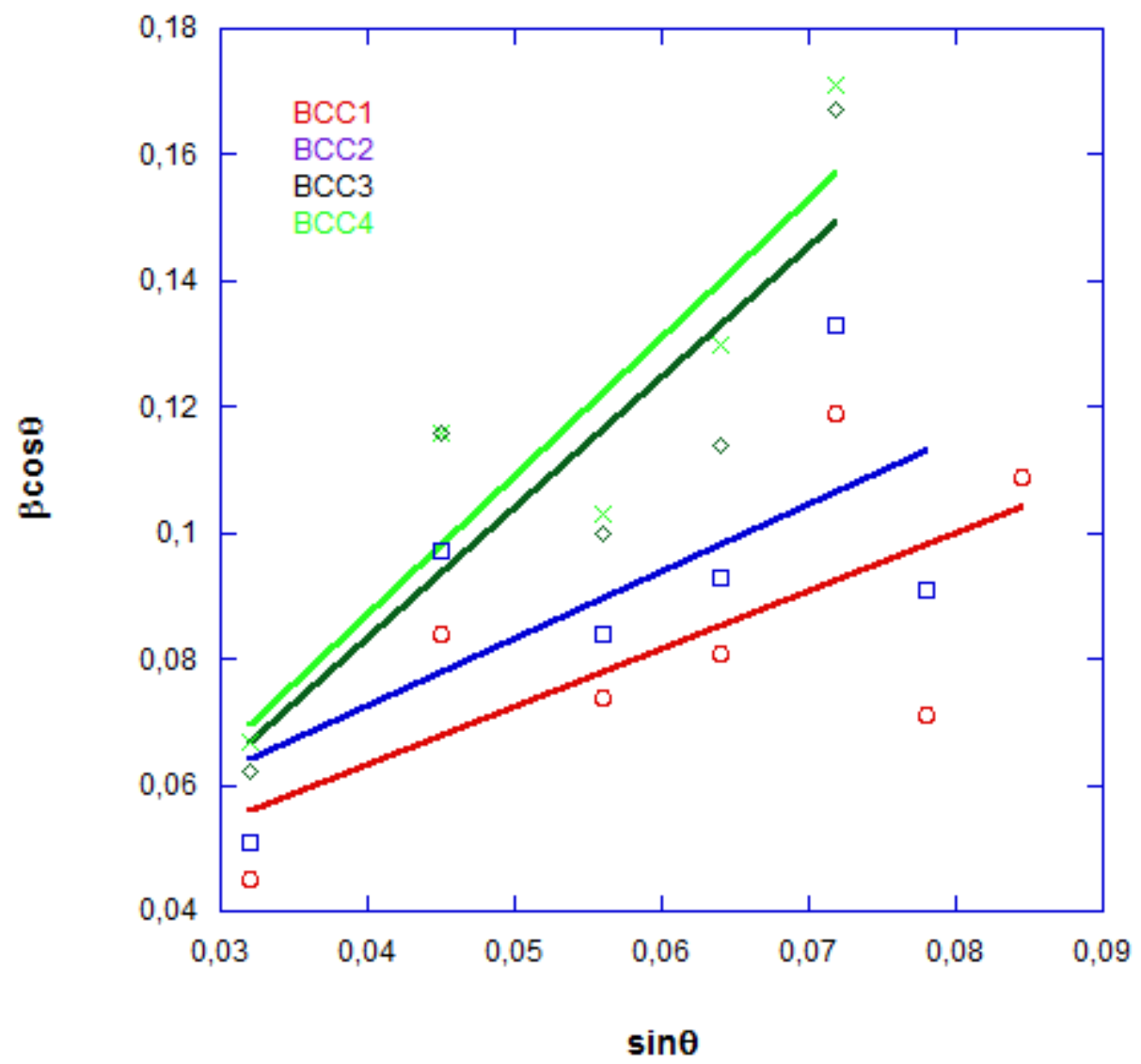

Figure 3a: Evolution of the peak broadening (Williamson-Hall plots) for samples BCC1, BCC2, BCC 3 and $\mathrm{BCC} 4$ at $400^{\circ} \mathrm{C}$. 


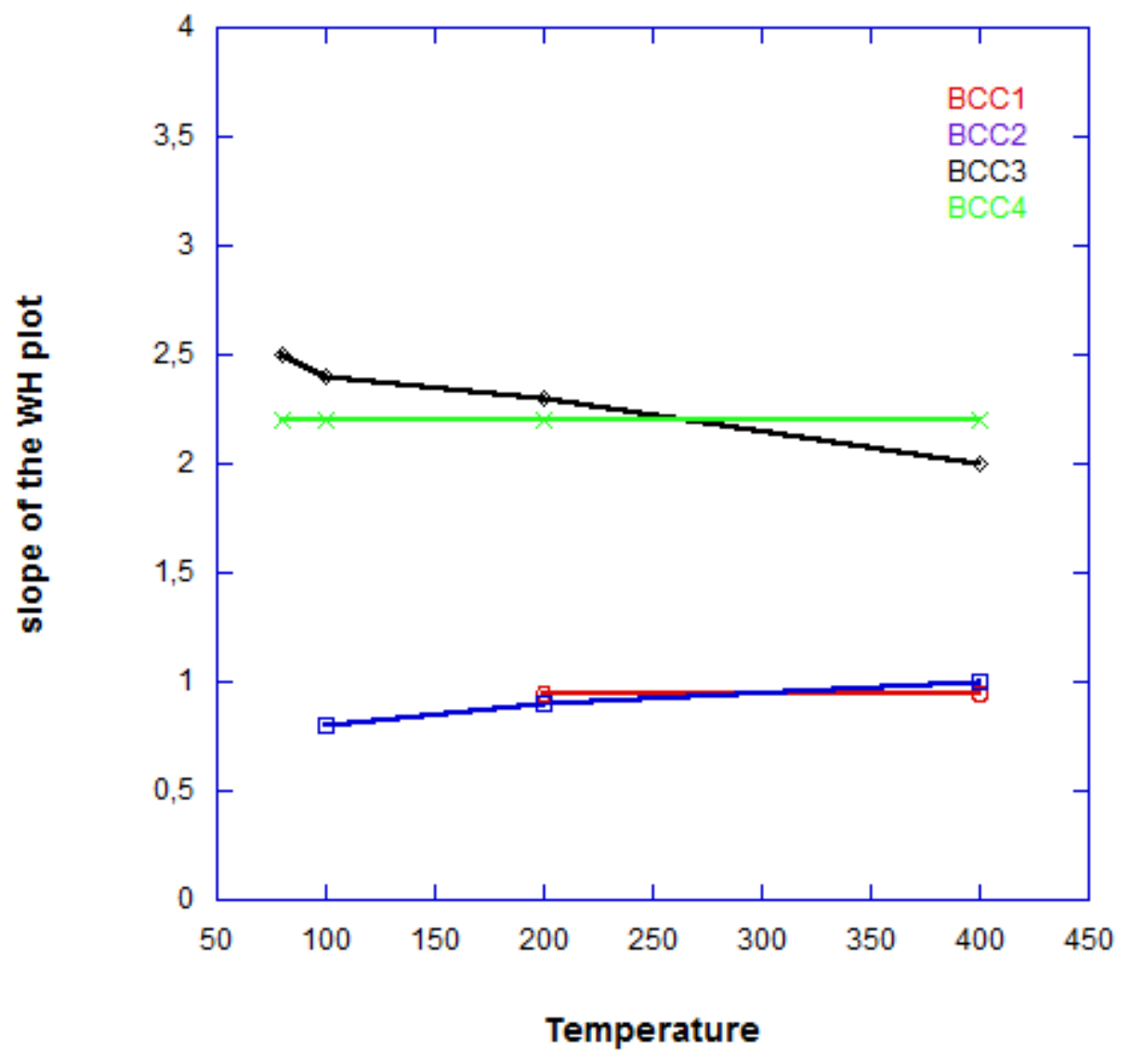

Figure 3b: Evolution of the strain contribution to peak broadening as a function of temperature 


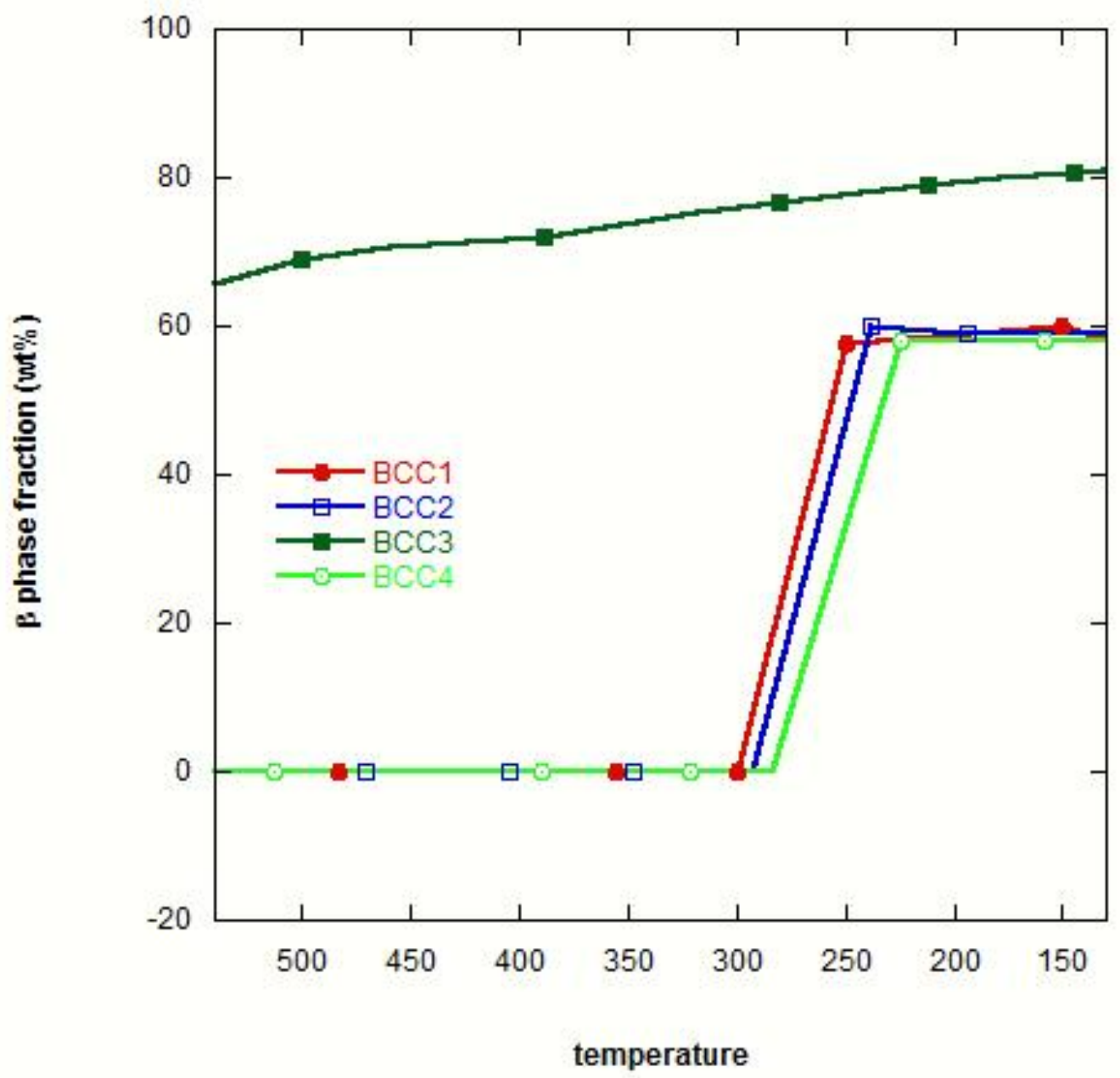

Figure 4a: Evolution of the $\beta$ phase weight fraction in the course of the hydrogen absorption process (decreasing temperature). 


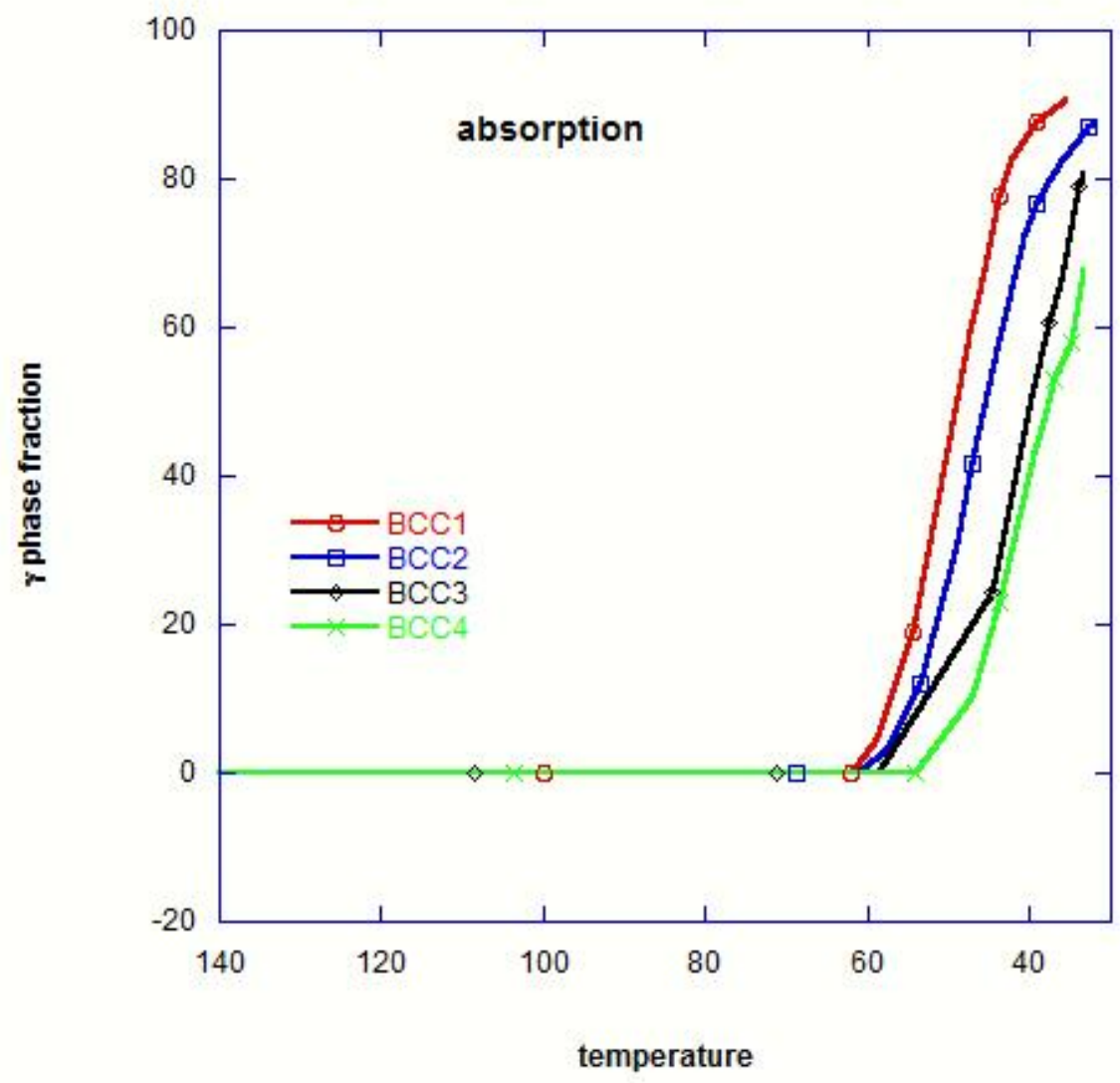

Figure 4b: Evolution of the $\gamma$ phase weight fraction in the course of the hydrogen absorption process (decreasing temperature). 


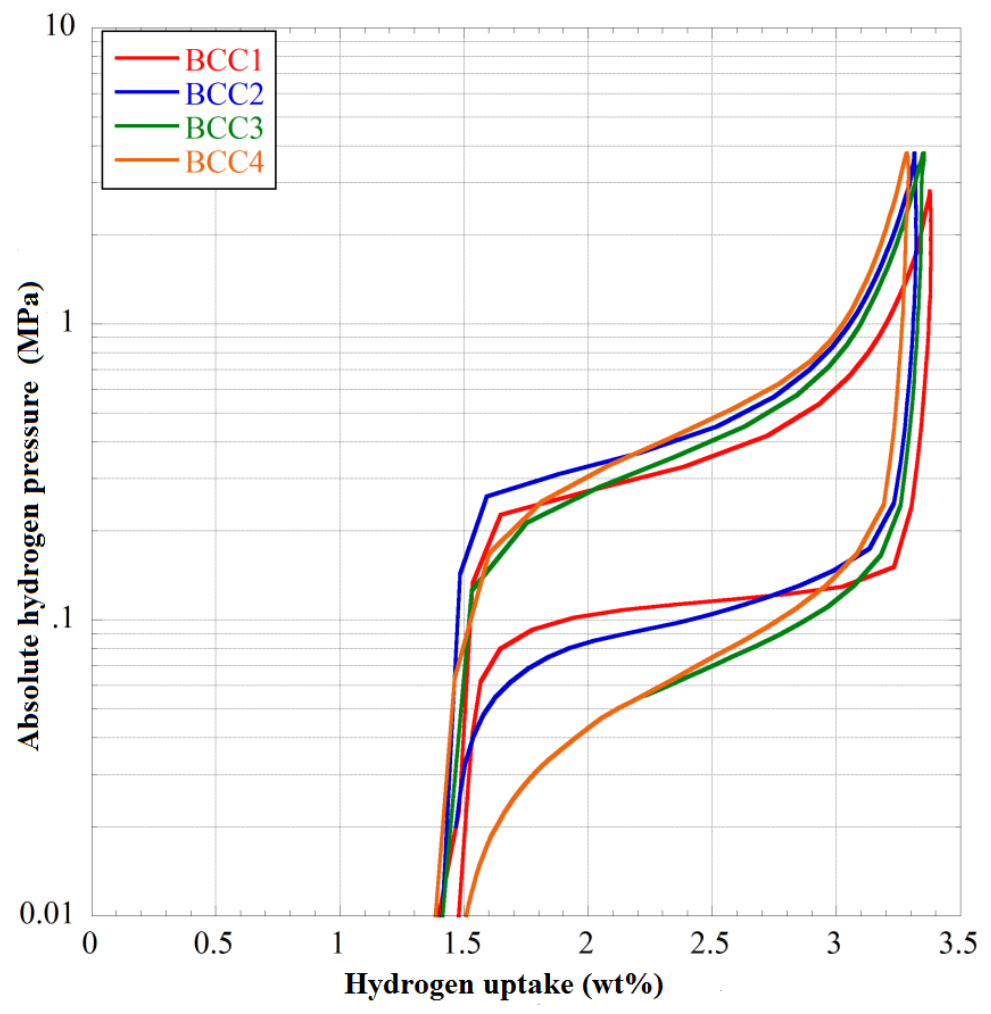

Figure 5: P-C Isotherms of samples $\mathrm{V}_{(1-\mathrm{x})}\left(\mathrm{Ti}_{0,8} \mathrm{Cr}\right)_{\mathrm{x}}$ recorded at $20^{\circ} \mathrm{C}$ 